\title{
Balkanologie
}

Balkanologie Revue d'études pluridisciplinaires

Vol. VIII, $n^{\circ} 1 \mid 2004$

Volume VIII Numéro 1

\section{Nicolau (Irina), Vagabondage dans les Balkans. Une incursion subjective au pays des Aroumains}

La Tour d'Aigues : Éditions de l'Aube, 2003. 190 p. (Traduit du roumain par Marianne Mesnil)

\section{Gilles de Rapper}

\section{OpenEdition}

\section{Journals}

Édition électronique

URL : http://journals.openedition.org/balkanologie/2078

DOI : 10.4000/balkanologie.2078

ISSN : 1965-0582

Éditeur

Association française d'études sur les Balkans (Afebalk)

Édition imprimée

Date de publication : 1 juin 2004

ISSN : 1279-7952

Référence électronique

Gilles de Rapper, «Nicolau (Irina), Vagabondage dans les Balkans. Une incursion subjective au pays des Aroumains », Balkanologie [En ligne], Vol. VIII, n 1 | 2004, mis en ligne le 21 janvier 2010, consulté le 17 décembre 2020. URL : http://journals.openedition.org/balkanologie/2078 ; DOI : https://doi.org/ 10.4000/balkanologie.2078

Ce document a été généré automatiquement le 17 décembre 2020.

(c) Tous droits réservés 


\title{
Nicolau (Irina), Vagabondage dans les Balkans. Une incursion subjective au pays des Aroumains
}

\author{
La Tour d'Aigues : Éditions de l'Aube, 2003. 190 p. (Traduit du roumain \\ par Marianne Mesnil)
}

\section{Gilles de Rapper}

\section{RÉFÉRENCE}

Nicolau (Irina), Vagabondage dans les Balkans. Une incursion subjective au pays des Aroumains, La Tour d'Aigues : Éditions de l'Aube, 2003. 190 p. (Traduit du roumain par Marianne Mesnil).

Vagabondage dans les Balkans est un livre très personnel et très attachant. Irina Nicolau, qui fut longtemps ethnologue à l'Institut d'ethnographie et de folklore de Bucarest, rapporte les traditions familiales transmises par son père, Aroumain originaire de Doliani (aujourd'hui Koumaria, à l'ouest de Véria, en Grèce). La première partie du livre, après un avant-propos de la traductrice, explore de façon décousue un certain nombre de thèmes (religion, mariage, langue et alphabet,...) ; la seconde est une sorte de dictionnaire des lieux aroumains, d'Aminciu (Metsovo) à Zagore (Zagori), dans laquelle chaque ville ou village est présenté à travers les traditions orales et surtout les récits des érudits. Signalons tout de suite le caractère imprécis de la toponymie, qui finit par être gênant; le parti pris de l'auteur semble être de donner la forme aroumaine de tous les toponymes, quelle que soit leur forme officielle dans les pays où les localités se trouvent aujourd'hui, mais cela rend souvent difficile leur identification et localisation (une carte aurait par ailleurs permis de situer les moins connus d'entre eux), d'autant plus qu'ils apparaissent fréquemment sous des graphies différentes (Farsari et Frachari pour Frashër, Nicolitsa et Nicoulitsa pour Nikolicë, etc.). Une bibliographie sommaire (où ne figurent ni le livre de Athanasie Hâciu auquel l'auteur se 
réfère constamment dans la seconde partie, ni celui de Burileanu qui semble être de même une de ses sources importantes), un glossaire et une bio-bibliographie d'Irina Nicolau complètent le livre.

Il ne s'agit donc pas ici d'un ouvrage d'histoire ou d'ethnologie, même si l'auteur a puisé dans la littérature consacrée aux Aroumains pour confronter les sources familiales à celle de l'histoire et de l'ethnographie. Les multiples anecdotes à propos d'ancêtres plus ou moins lointains et les réflexions plus personnelles de l'auteur (qui admet que les traditions familiales comportent un certain nombre d'exagérations et de manipulations) forment plutôt un tableau impressionniste de la présence aroumaine dans les Balkans à l'époque ottomane comme à celle des États-nations. Personnages remarquables, lieux, coutumes, attitudes face à la vie, langue, hypothèses diverses sur l'origine et l'histoire des Aroumains, tout est brossé à petites touches très évocatrices. On retiendra en particulier la mention des conversions à l'islam (alors que les Aroumains sont généralement perçus comme étant restés en dehors du processus d'islamisation), les exemples d'interactions avec le pouvoir ottoman et les gouverneurs locaux (Ali pacha de Ioannina fait des apparitions régulières) ainsi que la place occupée par le bétail (moutons et chevaux en particulier) non seulement dans la vie des pasteurs, mais aussi dans les représentations, la langue et les valeurs des Aroumains urbanisés.

Usant volontiers d'un style oral, proche de celui des conteurs, et interpellant son lecteur (le titre original du livre est Haïde bre!), Irina Nicolau parvient à nous faire saisir de l'intérieur une partie de l'univers des Aroumains, et par-là même des Balkans. Ce qui frappe en effet est la ressemblance de nombreuses anecdotes et caractéristiques attribuées ici aux Aroumains avec celles que l'on rencontre chez les Grecs, les Bulgares ou les Albanais. Ainsi par exemple de la manière dont les femmes de la maison posent chacune à leur tour et par ordre d'âge décroissant les mêmes questions au visiteur sur sa famille et son activité (pp. 5354). Les histoires de conversions à l'islam de villages aroumains (p. 93) sont rapportées par Pouqueville (dont le nom est malheureusement mal orthographié tout au long du livre, comme celui du colonel Leake) à propos de villages albanais de la même région de Përmet (Voyage de la Grèce, 1826, tome 1, pp. 259-261), et Irina Nicolau nous apprend que l'évergète Evangelos Zappas (ou Vangjel Zhapa), que se disputent déjà Grecs et Albanais, était Aroumain (pp. 39-41). Il en est ainsi jusqu'à la polyvalence professionnelle de l'Aroumain, « homme total », pratiquant l'élevage et le commerce, l'artisanat et la médecine, qui pourrait s'appliquer à d'autres populations balkaniques (p.112). Au milieu de cet air de familiarité balkanique, tout se passe comme si la spécificité de chacun n'était faite que de nuances et de subtiles oppositions complémentaires: si le costume des Aroumains de Samarina est sobre, n'est-ce pas pour mieux marquer la différence avec les «tenues excentriques » et les " goûts douteux » des Albanais (p. 51)?

Quelles que soient ses limites en tant qu'ouvrage d'érudition, le livre d'Irina Nicolau a le grand mérite de donner des Balkans l'image d'un «monde de miettes » (p. 18) qui ne s'offre pas au regard qu'à travers les grandes constructions identitaires des nations, mais aussi à travers d'innombrables expériences et impressions individuelles. On espère donc la publication prochaine en français du deuxième volet de l'enquête, consacré au côté maternel, et grec, de la famille de l'auteur. 